\title{
EDUCAÇÃO INCLUSIVA: O QUE DIZEM OS DOCUMENTOS?
}

\author{
Beatriz Branco Maia \\ Marian Ávila de Lima e Dias \\ Universidade Federal de São Paulo
}

\begin{abstract}
Resumo
Dentre os textos do Ministério da Educação representativos da posição oficial sobre a educação inclusiva no Brasil, realizamos a análise de três documentos: as Diretrizes nacionais para a educação especial na educação básica (BRASIL, 2001); a Política nacional de educação especial na perspectiva da educação inclusiva (BRASIL, 2007); e Educação inclusiva: a fundamentação filosófica (ARANHA/SEESP, 2004). A análise evidencia que os textos apresentam categorias argumentativas de defesa da educação inclusiva principalmente a partir de valores morais e argumentos legalistas: para que a lei seja cumprida e para contribuir com uma sociedade justa, solidária e mais igual. Apesar de os documentos mencionarem a adaptação dos sistemas escolares, verificamos que estes pouco se detêm sobre o fazer pedagógico e as práticas inclusivas no ambiente escolar. $\mathrm{O}$ texto conclui que as contradições e inconsistências observadas na implementação da educação inclusiva também estão presentes nos próprios textos que buscam fornecer seus fundamentos.
\end{abstract}

Palavras-chave: educação; educação inclusiva; fundamentos filosóficos. 


\title{
INCLUSIVE EDUCATION: WHAT DO THE DOCUMENTS SAY?
}

\begin{abstract}
This paper analyzes three documents issued by the Brazilian Education Ministry, which represent the official position on Brazilian inclusive education. The studied documents were: National guidelines to special education in elementary education (BRASIL, 2001); National policy of special education in the perspective of inclusive education (BRASIL, 2007); and Inclusive education: the philosophic grounding (ARANHA/ SEE SP, 2004). The analysis of the texts shows that the argumentative categories in defense of the inclusive education were based mostly on moral values and legal arguments: there must be an inclusive education in order to obey the law and to contribute with a fairer, more solidarity and egalitarian society. Although the documents do mention the school systems' adaptation few is said about the pedagogical practice itself, or about the inclusive resources and practices in the school environment. It concludes that the contradictions observed in the inclusive education implementation are also repeated in the very texts that provide its foundations.
\end{abstract}

Key words: education; inclusive education; philosophical foundations 


\section{Introdução}

A proposta da educação inclusiva, com a convicção de que todos têm o direito a frequentar sala de aula regular em um mesmo regime escolar tem sido, nas últimas décadas, defendida como a estratégia política, pedagógica e social a ser adotada pelo sistema escolar.

No Brasil, a implementação da educação inclusiva encontra ampla variação - a composição das classes, a metodologia, o currículo e a avaliação apresentam-se de formas distintas nas escolas (CASCO; DIAS, 2011). Do mesmo modo, são diversas e por vezes contraditórias as recomendações das secretarias municipais e estaduais denotando a fragilidade no estabelecimento de uma diretriz política nacional para a educação inclusiva. Um aspecto dessa fragilidade evidencia-se no fato de que, frequentemente, mesmo nas instituições escolares que se consideram inclusivas, ainda são observadas situações de segregação vivenciadas pelos alunos considerados em situação de inclusão (CROCHÍK et al., 2009).

Pensando nas condições atuais da implementação da educação inclusiva no país, o presente trabalho expõe a pesquisa e a análise de três textos do Ministério da Educação (MEC) que representam a posição política oficial da educação inclusiva no Brasil. Eles apresentam princípios, argumentos e fundamentações para a implementação da educação inclusiva.

Consideramos a educação inclusiva como a melhor proposta no cenário contemporâneo, uma vez que ela possibilita que todos tenham acesso e permanência com qualidade em um mesmo sistema escolar. Ressaltamos que a educação inclusiva não se refere apenas a estabelecer estratégias de ensino para um determinado grupo de alunos, em que o alvo principal é o aluno com deficiência, mas a uma concepção da escola capaz de incluir efetivamente todos. Desta forma, acreditamos que o estudo de seus fundamentos trará maior consistência para a sua defesa, bem como possibilitará a construção de uma crítica aos impasses enfrentados pela educação inclusiva em sua implementação. 
O trabalho será dividido em três tópicos a fim de realizar uma análise sobre a educação inclusiva: o primeiro refere-se a uma breve retomada histórica da educação no Brasil, buscando compreender a passagem da perspectiva de educação especial para educação inclusiva estabelecendo uma contextualização da educação inclusiva na perspectiva da posição oficial do Ministério da Educação (MEC), bem como a forma com que essa modalidade de educação se insere na organização daquele ministério. Em seguida apresentaremos a metodologia e os documentos coletados. No terceiro tópico faremos uma análise dos três documentos escolhidos estabelecendo categorias argumentativas utilizadas nos textos de modo a auxiliar na compreensão da fundamentação da concepção de educação inclusiva adotada em nosso país.

\section{A educação da pessoa com deficiência: da segregação à inclusão}

Para compreender as diversas formas de educação voltadas às pessoas significativamente diferentes é preciso fazer um breve histórico sobre as principais concepções que permearam e ainda permeiam as propostas para a educação voltada aos significativamente diferentes, bem como suas posições na sociedade. No Brasil do século XIX, a ideia de que seria possível alguém desviante receber algum tipo de instrução estava depositada apenas em algumas das pessoas com deficiência, mais especificamente nos jovens rapazes com deficiência visual ou auditiva. (JANNUZZI, 2004).

A partir do século XX a institucionalização passa a ser criticada por alguns teóricos naquele período. A principal objeção era a de que os serviços oferecidos não contribuíam para um desenvolvimento e participação social daquelas pessoas (JANNUZZI, 2004). Mantoan e Prieto (2006) também apontam as fragilidades na aplicação daquele sistema de serviços:

\footnotetext{
não foi oferecido o referido conjunto de serviços de maneira a garantir que o encaminhamento respeitasse as características e as necessidades das pessoas; o encaminhamento para a educação especial não se justificava pela necessidade do aluno, e sim por este ser rejeitado na classe comum; não foram seguidos os princípios de transitoriedade, ou seja, de permanência do aluno em ambientes exclusivos de educação especial por tempo determinado (MANTOAN; PRIETO, 2006, p.39).
}

Olh@res, Guarulhos, v. 3, n. 1, p. 194-218. Maio, 2015. 
Tais críticas tomaram força também pelo fato de um grande número de pessoas estarem em situações improdutivas, ou seja, fora do mercado de trabalho. Após a segunda metade do século XX surge o paradigma da normalização, com a ideia de oferecer condições "próximas ao normal” para que os indivíduos com deficiências tivessem uma vida nos padrões estabelecidos pela sociedade (ARANHA, 2001).

Por volta de 1970, a partir da ideologia na normalização surge o paradigma da integração, na perspectiva de oferecer espaço e atendimento para que estas pessoas pudessem se encaixar nas condições "normais" e pudessem ser inseridas na escola comum. As principais críticas começam a aparecer, pois o objetivo desse tipo de atendimento era apenas para que as pessoas se integrassem às forças de produção, com pouca ou nenhuma relação com a aprendizagem de conteúdos formais e a transmissão de bens culturais da humanidade para aquela parcela da população. Assim, surgem as primeiras reivindicações quanto à organização desses serviços educacionais para que fossem baseadas no respeito, na honestidade, na justiça e na cidadania. Ganha força o paradigma de suportes compreendendo que o acesso aos recursos constituem em direito da pessoa com deficiência (ARANHA, 2001). A perspectiva da educação inclusiva começa a tomar forma na década de 1980, consolidando-se como marco político e princípio pedagógico na década seguinte.

\subsection{Da educação especial à educação inclusiva}

A educação especial para Parrila (1992 apud, GONZÁLEZ, 2002, p. 20)

é uma ação educativa, de fins equiparáveis aos da educação geral, mas que atua com base em alguns recursos educacionais específicos postos à disposição de qualquer pessoa, que em alguns casos poderão ser necessários de forma temporal e em outros de forma mais contínua e permanente. 
Já na perspectiva inclusiva a grande mudança está na reorganização de todo sistema educacional que deve ser redesenhado para oferecer respostas democráticas a todos os cidadãos, com ou sem deficiências.

De acordo com Matos e Mendes (2014) o movimento pela inclusão surgiu nos Estados Unidos durante a década de 1980. Naquele momento, surgiram duas oposições ao paradigma da educação especial: os "inclusivistas", que acreditavam que apenas a inserção na classe regular não garantia educação de qualidade à todos e afirmavam a necessidade da manutenção de outros serviços além da sala comum; e os "inclusivistas totais" que consideravam a inserção na escola como o único modo de efetivação de uma educação para todos de fato, favorecendo a diversidade.

Em 1990 ganha mais força o movimento de inclusão no acesso aos bens e direitos sociais. Isso faz com que a busca por uma educação em sintonia com os movimentos de consolidação da democracia impulsione a proposta da educação inclusiva. A Conferência Mundial de Educação Para Todos, a Declaração de Salamanca e a Conferência Mundial sobre as Necessidades Educacionais Especiais exemplificam esse movimento e provocam reformas educacionais em todo o mundo.

Assim, sai de cena o aluno com deficiência, protagonista da educação especial, e entra em cena o aluno em situação de inclusão por pertencer a um grupo tradicionalmente excluído da educação regular: indígenas, ciganos, crianças e jovens em situação de rua ou em conflito com a lei passam a ser, além daqueles com deficiências, também considerados na perspectiva inclusiva (CASCO; DIAS, 2011).

\subsection{A educação inclusiva hoje}

O movimento da educação inclusiva é um dos frutos da tensão entre as lutas por garantias de direitos civis contrapostos à tendência das sociedades capitalistas em ampliar mercados consumidores e a massa de trabalhadores. 
Uma vez que o século XX consolida a ideia de igualdade social entre os seres humanos, passamos a ter a convicção de que todos podem frequentar a escola, sem distinções. Porém, segundo Crochík (et al., 2009, p.41) "a estrutura da nossa sociedade é responsável pela constante exclusão de vários grupos”. Pensando nessa concepção, ao mesmo tempo em que o ingresso de todas as crianças na escola se torna "natural", historicamente tal ingresso se organizou e ainda se organiza baseado em uma padronização do alunado, em busca de uma possível otimização do ensino e da aprendizagem em que as diferenças e o diferente não possuem espaço.

Segundo Carvalho (2004), pairam dúvidas a respeito da proposta de implementação da inclusão educacional, pois se evidenciam os motivos relacionados ao atendimento de interesses econômicos na educação como meramente um mecanismo para formar indivíduos produtivos, inseridos no mercado de trabalho. Existiria, portanto, uma distorção da perspectiva inclusiva em que a educação seria apenas um investimento capaz de aumentar o número de alunos em sala de aula e, consequentemente, ampliar o número de futuros trabalhadores bem como da massa excedente de mão de obra de forma. Assim, o problema não está apenas na exclusão, está também na inclusão marginal, pois, segundo José de Souza Martins, "na medida em que a sociedade capitalista desenraiza, exclui, para incluir de outro modo, segundo suas próprias regras, sua própria lógica, o problema está justamente nessa inclusão.” (MARTINS, 1997, p. 28).

Diante de tal contexto, defende-se a educação inclusiva de forma a buscar o desenvolvimento de uma educação com a participação de todos que envolva as capacidades cognitivas, afetivas e sociais, ou seja, uma educação que desenvolva as diversas capacidades de todos os indivíduos de modo que sua formação possibilite refletir sobre tais contradições.

\subsection{Perspectivas e definições acerca do sistema educacional inclusivo}


Para Stainback e Stainback (1999) a educação inclusiva, em sentindo amplo, é definida como "prática da inclusão de todos - independentemente de seu talento, deficiência, origem socioeconômica ou origem cultural - em escolas e salas de aulas provedoras, onde todas as necessidades são satisfeitas" (STAINBACK; STAINBACK, 1999, p. 21). Segundo estes autores a proposta inclusiva favorece a todos os envolvidos na comunidade escolar. O sistema educacional inclusivo constitui a melhor forma de o ensino escolar caminhar na direção de promover a valorização da diversidade e da cooperação.

Booth e Ainscow (2011) em seu Index para a inclusão afirmam que o conceito de inclusão

é uma abordagem baseada em princípios ao desenvolvimento da educação e da sociedade. Está ligada à participação democrática no âmbito da educação e além dele. Não se trata de um aspecto da educação relacionado a nenhum grupo particular de crianças. Objetiva aportar coerência ao desenvolvimento de atividades que ocorrem sob diversos títulos de modo a estimularem a aprendizagem e a participação de todos: as crianças e suas famílias, professores, gestores e outros membros da comunidade (BOOTH; AINSCOW, 2011, p.19).

Segundo Casco e Dias (2011) como premissa da educação inclusiva estão o reconhecimento da diversidade e das necessidades de cada indivíduo no ambiente escolar. Os autores defendem que as práticas escolares "devem assegurar experiências formativas que promovam a participação e a aprendizagem efetiva de todos os alunos" (CASCO; DIAS, 2011, p.149).

Crochík e seus coautores $(2009 ; 2013)$ afirmam que a educação deve ocorrer para que tenhamos uma sociedade justa, favorecendo o convívio com os grupos significativamente diferentes como um elemento formador, com envolvimento de profissionais preparados e dotados de uma formação ética e política que desencadeiam engajamento da comunidade escolar. Para tais autores o caminho da educação inclusiva proporciona o desenvolvimento máximo dos alunos numa perspectiva de formação emancipatória, crítica, cooperativa e participativa. Os autores também afirmam que atualmente grande parte das tentativas de efetivação da educação inclusiva ainda não se desvinculou do paradigma da integração. 
A distinção entre educação integrada e educação inclusiva [...] indica que a primeira aceita os alunos com deficiência, faz algumas alterações importantes quer nas condições ambientais, quer na atenção a esses alunos, mas não faz modificações substanciais que incidam sobre todos os alunos, que é o caso da educação inclusiva que propõe novas modalidades de ensino que dão ênfase a trabalhos em grupo, ao desenvolvimento de currículos diferenciados para os alunos e avaliações também distintas, isto é, torna a escola mais apta para atender todos os alunos (CROCHÍK et al., 2009, p.45).

Acreditamos ser necessária a superação da integração, na perspectiva que esse movimento restringe-se a propor estratégias somente ao aluno com deficiência com a expectativa de que ele se adeque ao restante do grupo sem demandar dos demais qualquer transformação. Sob esta perspectiva, apoiar a educação inclusiva não significa defender uma participação e atenção exclusivas apenas aos alunos com deficiências; ao contrário: é buscar a promoção de uma educação que considere todos os alunos a partir de suas necessidades.

\subsection{A decisão brasileira: o MEC e a educação inclusiva}

O Ministério da Educação (MEC) é um órgão do governo federal do Brasil cujas atividades não se restringem à educação, mas também às áreas de saúde, esporte e meio ambiente. Atualmente a sua estrutura está dividida em secretarias e subsecretarias, acima delas estão a Consultoria Jurídica, o Gabinete do Ministro e o Conselho Nacional de Educação. Dentre as diversas secretarias está a Secretaria de Educação Continuada, Alfabetização, Diversidade e Inclusão (SECADI):

O objetivo da Secadi é contribuir para o desenvolvimento inclusivo dos sistemas de ensino, voltado à valorização das diferenças e da diversidade, à promoção da educação inclusiva, dos direitos humanos e da sustentabilidade socioambiental, visando à efetivação de políticas públicas transversais e intersetoriais. (Secretaria de Educação Continuada, Alfabetização, Diversidade e Inclusão - apresentação. Disponível em <portal.mec.gov.br>. Acessado em 19 de julho de 2014).

Em decorrência das Declarações internacionais assinadas pelo Brasil nas últimas décadas, o MEC, assume o papel de regulamentar, divulgar e fornecer 
diretrizes para a educação inclusiva como modelo a ser adotado nacionalmente. Também busca formas de contribuir com a implementação dessa modalidade de educação. Daí a importância em pesquisar seus documentos a fím de analisar suas argumentações para tal implementação.

Diante desse cenário, o presente trabalho apresenta uma pesquisa de caráter qualitativo no campo da educação, que busca investigar os argumentos que fundamentam a educação inclusiva em três documentos publicados pelo MEC.

\section{Método e documentos coletados}

O recorte metodológico escolhido foi a pesquisa documental. A pesquisa de documentos e textos produzidos pelo MEC é o caminho para a compreensão das diretrizes oficiais da prática educacional brasileira. Trata-se do material que deve chegar, com maior frequência e autoridade, às mãos das secretarias estaduais, municipais, equipes pedagógicas e de professores. Por meio desses textos são fornecidas noções do que seja a educação inclusiva, seus argumentos, suas justificativas e a fundamentação para sua implementação. Assim, o levantamento e a análise de seus fundamentos podem contribuir para a elaboração de uma perspectiva crítica sobre a educação inclusiva.

Trata-se de uma investigação exploratória que propõe como procedimento de coleta a pesquisa documental de fontes primárias (MAINGUENAU, 2005). A necessidade de estudo dos fundamentos da educação inclusiva coloca como central a importância dos documentos que a promulgam. Justifica-se, portanto, a escolha metodológica uma vez que este tipo de investigação é capaz de extrair e reordenar as informações contidas nesses documentos originais trazendo nova compreensão sobre temas e hipóteses de interesse (LÜDKE; ANDRE, 1986), o que permite a construção de um repertório críticoargumentativo sobre seus fundamentos.

Delimitamos como o escopo desta pesquisa documentos nacionais disponíveis e considerados pelo próprio MEC como aqueles que fornecem as bases e diretrizes para a implementação da educação inclusiva. Consideramos que o 
MEC, em especial a SECADI, tem credibilidade e representatividade nos documentos que elaboram, critérios essenciais para esse tipo de investigação.

As etapas de classificação dos documentos, análise e levantamento dos tipos de argumentação foram realizadas após a leitura estrutural dos documentos. O processo de análise consistiu na identificação dos temas e ideias centrais que evidenciam os seus fundamentos, bem como os tipos de argumentos utilizados em sua defesa. Os documentos estudados foram:

1) as Diretrizes nacionais para a educação especial na educação básica (BRASIL, 2001);

2) a Política nacional de educação especial na perspectiva da educação inclusiva (BRASIL, 2007); e

3) o texto Educação inclusiva: a fundamentação filosófica (ARANHA/SEESP, 2004).

Promulgados pelo Ministério da Educação (MEC), eles representam a posição política oficial da educação inclusiva. Uma vez que o Brasil adota a educação inclusiva como "perspectiva" da educação especial, temos de saída um impasse: dois dos documentos norteadores têm como princípio a educação especial. A educação inclusiva é ignorada (como é o caso do primeiro documento) ou aparece como elemento secundário (como no segundo documento analisado). Apenas no terceiro documento essa modalidade de educação ocupa a centralidade do texto. Tais documentos são, até hoje, os que servem de base para a educação inclusiva em nosso país, o que de partida evidencia a imprecisão não apenas na terminologia, mas, sobretudo nos princípios educacionais adotados.

\subsection{Contextualização dos documentos}

\subsubsection{Diretrizes nacionais para a educação especial na educação básica (BRASIL, 2001)}


O texto diretrizes nacionais para a educação especial na educação básica foi elaborado para a implementação da Educação Inclusiva no Brasil, e foi instituído pela Resolução CNE/CBE ${ }^{\circ} 2$, de 11 de setembro de 2001, com fundamento no Parecer CNE/CBE 17/2001.

Os estudos anteriores a esse documento apresentam questionamentos sobre o atendimento à crianças e alunos especiais, e dentre alguns documentos norteadores estão: (1) "Proposta de Inclusão de itens ou Disciplina acerca dos Portadores de Necessidades Especiais nos currículos dos cursos de $1^{\circ}$ e $2^{\circ}$ graus"; (2) Desafios para a Educação Especial frente à lei de Diretrizes e Bases da Educação Nacional"; (3) "Formação de Professores para a Educação Inclusiva"; (4) "Recomendações aos Sistemas de Ensino"; e (5) "Referenciais para a Educação Especial".

Segundo o próprio documento a partir das interrogações voltadas para o assunto, configura-se a necessidade de elaboração de normas para o atendimento da significativa parcela da população que apresenta necessidades educacionais especiais. Embora utilize o termo "necessidades educacionais especiais o texto também afirma o compromisso com a construção coletiva de condições para atendimento educacional à todos.

\subsubsection{Política nacional de educação especial na perspectiva da educação inclusiva (Brasil, 2007)}

A política nacional de educação especial na perspectiva da educação inclusiva é um documento elaborado pela equipe da SECADI em parceria com professores e pesquisadores nas áreas de inclusão social e escolar, políticas educacionais, acessibilidade, currículo etc.

Apresenta panorama histórico e normativo da educação especial, indicadores de acesso à educação básica (dados do Censo/MEC/INEP), perspectiva da educação inclusiva garantindo oferta de educação integradora, e por fim determina diretrizes da política nacional que garantem reorganização dos sistemas de ensino para atendimento educacional a todos no sistema regular de 
ensino. O documento afirma que "acompanha os avanços do conhecimento e das lutas sociais, visando constituir políticas públicas promotoras de uma educação de qualidade para todos os alunos” (BRASIL, 2007, p.05).

\subsubsection{Educação inclusiva: a fundamentação filosófica (ARANHA/SEESP, 2004)}

Elaborado pela então Secretaria de Educação Especial do MEC (atualmente SECADI) o texto é parte de uma série com mais três volumes "Educação inclusiva: o município", "Educação inclusiva: a escola", e "Educação inclusiva: a família". O texto aborda os princípios norteadores da Educação inclusiva mencionando outros textos relevantes no âmbito nacional e internacional, considerando a escola um espaço de construção da cidadania, fundamentada pela valorização da diversidade e da igualdade a fim de promover a paz e uma sociedade justa e democrática.

\section{Classificação dos documentos}

Segundo o dicionário Houaiss "diretriz" é um "esboço de um plano, projeto, orientação, diretiva; norma de procedimentos, conduta" (HOUAISS, 1999, p. 262). Dessa maneira, é possível afirmar que o primeiro documento é de ordem normativa, ou seja, são contextualizadas as Diretrizes a serem seguidas nos sistemas de ensino que orientam a implementação da educação inclusiva.

As políticas nacionais estabelecem os objetivos para o país de forma a orientar ações para tal conquista. No caso da política nacional de educação especial na perspectiva da educação inclusiva encontram-se "recomendações" para que a educação seja de qualidade e para todos. 
O terceiro documento pretende fornecer uma "fundamentação filosófica", supostamente apresentando os "princípios básicos", os valores que sustentam a proposta da educação inclusiva.

\subsection{Análise dos fundamentos da educação inclusiva nos documentos do MEC}

\subsubsection{Diretrizes nacionais para a educação especial na educação básica (BRASIL, 2001)}

\subsubsection{Categorias argumentativas}

Analisando o documento é possível encontrar cinco categorias argumentativas para a defesa da educação especial.

A primeira categoria argumentativa é de cunho moral, apontando para valores da humanidade, defendendo uma educação capaz de promover paz, solidariedade e justiça. De acordo com o documento o processo educativo é social e transformador e deve trabalhar em prol de uma sociedade justa e livre, valorizadora das diferenças para alçar uma “cultura de paz”. Sendo assim, não podem ser excluídos desse processo aqueles que não seguem padrões de normalidade, como os alunos significativamente diferentes. "Se o nosso sonho e o nosso empenho são por uma sociedade mais justa e livre, precisamos trabalhar desde a escola o convívio e valorização das diferenças, base para uma verdadeira cultura de paz" (BRASIL, 2001, p.5).

O texto apresenta a promoção da igualdade como condição necessária para a garantia de uma educação para todos. Defende a universalização do ensino enfatizando a atenção à diversidade e os ajustes necessários dos sistemas de ensino para criar e manter condições justas de atendimento aos alunos como forma de garantir igualdade no ensino escolar e, principalmente, no acesso à escola. De acordo com o texto "toda e qualquer pessoa digna e merecedora de respeito de seus semelhantes tem o direito a boas condições de vida e à oportunidade de realizar seus projetos" (BRASIL, 2001, p.24). 
A ideia de equidade também fundamenta o documento. É possível verificar tal argumento a partir da afirmação de que "a diversidade dos alunos requer diversidades de aprendizagens", no sentido de que cada indivíduo requer diferentes estratégias pedagógicas que devem ser "parte de um projeto educacional e social de caráter emancipatório e global" (BRASIL, 2001, p.20). Dessa maneira, exprime a ideia de que uma medida compensatória seria o caminho para eliminar as barreiras de adequação ao processo educacional.

O documento aponta ainda que é necessário assegurar oportunidades diferenciadas na busca por igualdade: "o princípio de equidade reconhece a diferença e a necessidade de haver condições diferenciadas para o processo educacional" sendo "um passo decisivo para a constituição de uma sociedade justa e solidária" (BRASIL, 2001, p.26).

Outro exemplo de trecho em que a argumentação é de cunho moral relacionase à função social da escola de "propiciar ações que favoreçam interações sociais, [...] a partir de práticas heterogêneas e inclusivas" (BRASIL, 2001, p.28), no âmbito da unidade escolar e no âmbito do sistema de ensino, para valorização da diversidade, sendo também uma categoria de fundamentação da educação inclusiva.

Uma segunda categoria argumentativa é a legalista. As Diretrizes apontam que é necessário respeitar os dispositivos legais que garantem a educação especial. Essa categoria argumentativa é ilustrada pela dedicação do texto em compilar os mais diversos dispositivos legais em um item sobre os fundamentos da organização dos sistemas de ensino. Logo em seu início o documento traz dez páginas de citações literais de trechos de declarações internacionais, da constituição do país, de leis e demais pareceres.

Em seu desenvolvimento o documento apresenta como terceira categoria de argumentação a função reparadora. Exemplifica tal argumento com a Educação de Jovens e Adultos, afirmando que esta promove a restauração de um direito à escola de qualidade, o que foi historicamente negado. A função equalizadora é uma categoria dentro do documento cuja origem é uma dívida da sociedade, e está presente ao comparar as oportunidades no mercado de trabalho para aqueles que "estão na vida ativa" e para aqueles "desprovidos de bens básicos Olh@res, Guarulhos, v. 3, n. 1, p. 194-218. Maio, 2015. 
como a leitura e a escrita" (BRASIL, 2001, p.23). Ainda nessa categoria argumentativa, outro exemplo encontrado no documento é o resgate da dívida social para com os indivíduos que apresentaram necessidades especiais ao longo da trajetória histórica da educação especial no país (movimentos de segregação). As Diretrizes defendem a necessidade de reestruturar o sistema de ensino de modo a contemplar os alunos com "necessidades educacionais especiais" como cidadãos de direito. Dessa forma, de acordo com o documento, o principal direito a ser alcançado "refere-se à preservação da dignidade e à busca da identidade dos cidadãos" por existir uma "dívida social a ser resgatada" (p.22). Porém, evidencia-se que apenas as pessoas com algum tipo de deficiência ou "necessidade educacional especial" são aquelas com quem a sociedade está em dívida, ficando excluídas do cenário escolar os desviantes de outra natureza.

As Diretrizes utilizam como quarta categoria argumentativa a questão pedagógica. O texto afirma que o aluno está no centro do processo pedagógico e a atenção à diversidade deve estar presente em todos os segmentos da comunidade, de forma que todos possam participar efetivamente nas instituições escolares: "em vez de focalizar a deficiência da pessoa, enfatiza o ensino e a escola, bem como as formas e condições de aprendizagem; em vez de procurar, no aluno, a origem do problema [...]" (BRASIL, 2001, p.33).

Um argumento diferente de todas as outras categorias mencionadas é o de utilizar os recursos da modalidade da educação especial na perspectiva inclusiva para alcance de rendimentos satisfatórios, como um compromisso do cumprimento de metas firmado com outras nações e estabelecido como uma das diretrizes a serem atingidas. Nas Diretrizes o atendimento educacional especializado no ensino regular e em classes comuns é meta política a fim de atingir um rendimento escolar satisfatório. Adotando claramente a proposta da educação especial, o texto afirma que sem intervenções fora da sala de aula muitos alunos não atingiriam o rendimento esperado.

\footnotetext{
A inclusão de alunos com necessidades educacionais especiais em classes comuns do ensino regular, como meta das políticas de educação, exige interação constante entre professor da classe comum e os dos serviços de apoio pedagógico especializado, sob pena de alguns educandos não atingirem rendimento escolar satisfatório." (BRASIL, 2011, p.51).
} 


\subsubsection{Análise}

A partir das afirmações do documento verifica-se uma distância da perspectiva da educação inclusiva e do fazer pedagógico. Nesse sentido a escola pouco é mencionada como espaço de educação e de aprendizagem de todos, e, principalmente para os alunos significativamente diferentes, sendo tomada como espaço de socialização, de reparação, de demonstração de cumprimento de metas políticas perdendo sua especificidade: ensinar e aprender. Ao longo do documento são ilustradas tais perspectivas e ao final do texto os autores as reafirmam "com a edição deste Parecer e as Diretrizes que o integram, este Colegiado está oferecendo ao Brasil [...] um caminho e os meios legais para a superação do grave problema educacional, social e humano que os envolve." (BRASIL, 2001, p.61-62). Assim, a superação e a reparação são evidenciadas no texto em detrimento às práticas pedagógicas escolares. Verificamos também que além de a escola e a prática pedagógica serem pouco mencionadas, quando citadas elas estão no sentido de metas políticas e não educacionais.

É importante ressaltar que ao tratar da educação especial e da educação inclusiva em um mesmo documento um grande paradoxo se apresenta pois não consideramos ser possível apresentar elementos norteadores da educação inclusiva - que é para todos - a partir do paradigma contemplado pela educação especial.

\subsubsection{Política nacional de educação especial na perspectiva da educação inclusiva (BRASIL, 2007)}

\subsubsection{Categorias argumentativas}

A Política nacional de educação especial na perspectiva da educação inclusiva (BRASIL, 2007) foi elaborada para o MEC pelo grupo de trabalho da política nacional de educação especial. $\mathrm{Na}$ apresentação do documento são elencadas algumas características dessa modalidade de educação e dos avanços da educação inclusiva. Segundo o texto, "a educação inclusiva constitui um 
paradigma educacional fundamentado na concepção de direitos humanos, que conjuga igualdade e a diferença como valores indissociáveis" (BRASIL, 2007, p.5). Nesta parte do texto, a primeira categoria argumentativa de defesa da educação inclusiva é na esfera dos valores morais: a promoção da igualdade, tendo em vista a superação de práticas discriminatórias.

Outra categoria argumentativa é de cunho legalista. Essa categoria é identificada pelo fato de o documento se dedicar a descrever leis já existentes sobre o tema: a Lei de Diretrizes e Bases da Educação Nacional 4024/61, a Constituição Federal de 1988, o Estatuto da Criança e do Adolescente, a Declaração Mundial de Educação Para Todos, a Política Nacional de Educação Especial, a Lei de Diretrizes e Bases da Educação Nacional vigente 9394/96, o Plano Nacional de Educação 10172/2001, além de mencionar decretos e programas governamentais sobre educação inclusiva.

Por fim, o documento se apropria do argumento da participação social e da inserção no mundo do trabalho: "as ações de educação especial possibilitam a ampliação de oportunidades de escolarização, formação para inserção no mundo do trabalho e efetiva participação social" (BRASIL, 2007, p.16).

\subsubsection{Análise}

É possível perceber uma crítica do texto às fragilidades de outros documentos da área. Mas, ao mesmo tempo em que faz isso, o próprio texto apresenta contradições. Ressaltamos como um dos argumentos mais contraditórios presentes nesse texto o fato dele abrir espaço aos atendimentos fora do espaço de ensino regular, ou seja: de forma segregada. Como exemplo, temos a ideia de uma "atuação pedagógica voltada para alterar a situação de exclusão, enfatizando a importância de ambientes heterogêneos que promovam a aprendizagem de todos os alunos" (BRASIL, 2007, p. 15) ao mesmo tempo em que o texto reafirma a perspectiva da educação especial no âmbito do atendimento especializado sendo que este é favorável "a formação dos alunos com vistas à autonomia e independência na escola e fora dela" (BRASIL, 2008, 
p. 16). Assim, o texto não avança na perspectiva da educação inclusiva uma vez que indica ser necessário o "atendimento" (termo característico da área da saúde e não da educação) do aluno em centro especializado fora da classe regular, o que é característico do modelo da educação especial.

Ao longo do texto diversas leis são explicitadas e postas como marcos de “evolução" rumo a uma efetivação da educação inclusiva: (1) LDBN 4024/61, (2) a reformulação 5692/71 da LBDN 4024/61, (3) a Constituição Federal de 1988, (4) o estatuto da criança e do adolescente, (5) a Declaração Mundial de Educação Para Todos, (6) a Declaração de Salamanca, (7) a Política Nacional de Educação Especial, (8) a LDBN 9394/96, (9) o decreto 3298/99, (10) as Diretrizes Nacionais para a Educação Básica, (11) o Plano Nacional de Educação - PNE lei n 10172/2001, o decreto n³ 3956/2001 que promulga a Convenção de Guatemala, (12) a resolução CNE/CP nº1/2002, (13) a lei 10436/02, (14) a portaria 2678/02, (15) o programa "Educação Inclusiva: direito à diversidade", (16) o documento "o Acesso de Alunos com Deficiência às Escolas e Classes Comuns da Rede Regular, (17) o decreto 5296/04, (18) o decreto 5626/05, (19) a Convenção sobre os Direitos das Pessoas com Deficiência, (20) o Plano Nacional de Educação em Direitos Humanos, o Plano de Desenvolvimento da Educação - PDE do Plano de Aceleração do Crescimento - PAC, e (21) o decreto 6094/2007.

De fato, não discordamos que as normativas dessa temática foram e são importantes para o avanço da educação na perspectiva inclusiva, mas, no texto, a referência às mudanças das leis é descrita de forma a parecer completamente dissociada das demandas sociais e históricas do Brasil e do mundo, sendo mera listagem sequencial e descontextualizada, distante das dificuldades dos alunos em situação de inclusão e das lutas dos movimentos sociais na busca por uma educação que inclua a todos.

O documento ao se alongar em citar as mais diversas legislações apenas reafirma a necessidade maior de um cumprimento de leis desconsiderando as especificidades dos alunos.

Se, de fato, cada novo documento ou legislação é um avanço perante as normativas anteriores, por que as leis se repetem? Se contribuem para uma Olh@res, Guarulhos, v. 3, n. 1, p. 194-218. Maio, 2015. 
educação mais justa e igual, por que é preciso publicar novos textos oficiais com os mesmos discursos? Nessa perspectiva, a leitura desses textos faz pensar que as leis mais recentes permanecem insuficientes para demarcar um avanço significativo na realidade das escolas públicas no tocante ao acesso dos alunos significativamente diferentes a essas escolas e, principalmente, aos aspectos pedagógicos ligados diretamente à aprendizagem desses alunos.

\subsubsection{Educação Inclusiva: a fundamentação filosófica (ARANHA/SEESP, 2004)}

\subsubsection{Categorias argumentativas}

Ao longo do texto percebemos quatro grandes categorias. Primeiramente o texto assume a defesa dos valores morais de igualdade, respeito à diversidade, justiça, democracia e liberdade como seus fundamentos. Porém, os argumentos morais são submetidos ao argumento legalista de forma que tais valores são compreendidos não por sua relevância moral, mas por fazerem parte das normas e, nessa perspectiva, o que é ressaltado é o respeito às legislações.

Dessa forma, a segunda categoria, predominante no documento, é a defesa ao cumprimento de leis. Tal defesa está presente no texto sob a forma de levantamento e descrição dos documentos orientadores da criação dos sistemas educacionais inclusivos no âmbito nacional e internacional. São mencionados: (1) A Declaração universal dos direitos humanos, (2) a Conferência mundial sobre educação para todos de Jomtien, (3) a Conferência mundial sobre necessidades educacionais especiais de Salamanca, (4) a Convenção interamericana para a eliminação de todas as formas de discriminação contra as pessoas portadoras de deficiência da Guatemala, (5) a Constituição Federal, (6) o Estatuto da Criança e do Adolescente, (7) a Política nacional para a integração da pessoa portadora de deficiência - Decreto 3298/99, (8) o Plano Nacional de Educação, (9) a Convenção interamericana para eliminação de todas as formas de discriminação contra as pessoas com deficiência, (10) as Diretrizes nacionais para a educação especial na educação básica, (11) os 
Saberes e práticas da inclusão na educação infantil, (12) o documento Educação Profissional - indicações para a ação: a interface educação profissional/educação especial e (13) o documento Direito à Educação subsídios para a gestão do sistema educacional inclusivo. $\mathrm{O}$ texto ainda finaliza pontuando mais orientações gerais, marcos legais, decretos, portarias do MEC, resoluções, um aviso circular e um parecer. Em um documento com esse caráter, é um fato marcante a constatação de que das 30 páginas que o compõem, 16 sejam dedicadas à descrição de leis, portarias e resoluções.

O texto ainda traz como último argumento em favor da educação inclusiva a ideia de uma educação para a paz:

\footnotetext{
uma proposta de educação para a paz deve sensibilizar os educandos para novas formas de convivência baseadas na solidariedade e no respeito às diferenças, valores essenciais na formação de cidadãos conscientes de seus direitos e deveres sensíveis para rejeitarem toda a forma de opressão e violência (ARANHA/SEESP, 2004, p.10).
}

Dessa forma, o documento afirma que através da educação inclusiva teríamos uma formação mais humana, solidária e cidadã.

\subsubsection{Análise}

Percebemos que os argumentos em prol da educação inclusiva explicitados defendem prioritariamente a obediência às leis. O texto também busca a promoção de valores morais, mas os aspectos educacionais são ignorados. Para um documento filosófico, é curioso notar a enorme quantidade de declarações, decretos e demais normativas que apenas enfatizam o argumento legalista.

$\mathrm{O}$ argumento de cunho supostamente filosófico, de uma educação para a paz, prevê a educação inclusiva como um meio para a promoção da paz valorizando a cidadania. Porém o documento propõe que a escola seja a responsável pela transformação na sociedade. Esse tipo de proposta desobriga a sociedade de se confrontar com suas limitações, opressões e desigualdades, depositando apenas na escola as esperanças de que algo se transforme. Dessa forma, a expectativa de encontrar nesse documento justificativas para a educação inclusiva não é atendida, na medida em que esta é compreendida, no documento, como um meio para a promoção de valores e não o contrário. 


\section{Considerações finais}

Afinal, segundo estes documentos, por que adotar a perspectiva inclusiva? Os textos analisados apresentam categorias argumentativas muito parecidas, prevalecendo à obediência a valores morais como igualdade e respeito à diversidade, mas, sobretudo, argumentos legalistas: a educação inclusiva é necessária para que a lei seja cumprida. Nessa segunda linha argumentativa o primeiro documento, diferentemente dos demais, ainda defende a necessidade de uma educação inclusiva a fim de que sejam cumpridas metas políticas para o alcance de rendimentos escolares satisfatórios, distante das metas pedagógicas, o que em nossa opinião explicita ainda mais a intenção de apenas colocar mais crianças e jovens na escola sem, de fato, incluí-los.

Apesar de os documentos mencionarem a adaptação dos sistemas escolares para uma inclusão de fato das crianças e jovens à escola e não o contrário, estes mesmos textos, ao apresentarem suas defesas e seus argumentos, pouco determinam sobre o fazer pedagógico e sobre recursos e práticas inclusivas no ambiente escolar, frequentemente restringindo suas proposições ao aluno com necessidades educacionais especiais ainda sob a perspectiva apenas da deficiência. Uma das conclusões a que chegamos após a análise empreendida foi a grande distância entre os documentos e as práticas pedagógicas escolares. A escola, o aluno, o ensinar e o aprender foram quase que totalmente ignorados. É inevitável questionar o distanciamento da relação que estes documentos estabelecem entre suas argumentações e a escola cotidiana e concreta.

Para assegurar avanços efetivos ao processo de implementação da proposta inclusiva é preciso refletir sobre a fundamentação do sistema educacional inclusivo e os princípios nos quais ela é baseada. Acreditamos que a democracia, a igualdade e o respeito à diversidade devem ser a base para a execução e a prática da proposta inclusiva capaz de consolidar uma educação que pode desenvolver o máximo dos alunos, com ou sem deficiência, 
Beatriz Branco Maia \& Marian Ávila de Lima e Dias

estigmatizados ou não, em uma formação participativa, colaborativa, crítica, reflexiva e emancipatória - uma aprendizagem para todos, sem discriminações. 


\section{Legislação consultada}

BRASIL. Ministério da Educação. Política Nacional de Educação Especial na Perspectiva da Educação Inclusiva - MEC, 2007.

BRASIL. Ministério da Educação. Diretrizes nacionais para a educação especial na educação básica. Brasília: Secretaria de Educação Especial - MEC; SEESP, 2001.

BRASIL. Ministério da Educação. Secretaria de Educação Continuada, Alfabetização, Diversidade e Inclusão - apresentação. Disponível em <portal.mec.gov.br>. Acessado em 19 de julho de 2014).

\section{Referências bibliográficas}

ARANHA, Maria Salete Fábio. Educação inclusiva: a fundamentação filosófica. Brasília: Ministério da Educação, Secretaria de Educação Especial, 2004.

ARANHA, Maria Salete Fábio. Paradigmas da relação entre a sociedade e as pessoas com deficiência. Revista do Ministério Público do Trabalho, ano 11, março de 2001.

BOOTH, Tony. AINSCOW, Mel. Index para a inclusão. Traduzido por: Mônica Pereira dos Santos e João Batista Esteves. Londres: CSIE, 2011.

CARVALHO, Rosita Edler. Educação inclusiva: com os pingos nos "is". Porto Alegre: Mediação, 2004.

CASCO, Ricardo; DIAS, Marian Ávila de Lima. Avaliação educacional e preconceito: contribuições da Teoria Crítica da Sociedade. Intermeio (UFMS), v. 17, p. 140-154, 2011.

CROCHÍK, José Leon; FRELLER, Cintia; DIAS, Marian Ávila de Lima; FEFFERMANN, Marisa; NASCIMENTO,Rafael Baioni; CASCO, Ricardo. Atitudes de professores em relação à educação inclusiva. Psicologia: Ciência e Profissão (Impresso), v. 29, p. 40-59, 2009.

CROCHÍK, José Leon; FRELLER, Cintia; DIAS, Marian Ávila de Lima; FEFFERMANN, Marisa; NASCIMENTO,Rafael Baioni; CASCO, Ricardo. Educação inclusiva: escolha e rejeição entre alunos. Psicologia \& Sociedade, 25 (1), p.174-184, 2013.

GONZÁLEZ, José Antonio Torres. Educação e diversidade: bases didáticas e organizativas. Porto Alegre: Artmed. 2002.

HOUAISS, Antônio. Minidicionário Houaiss da língua portuguesa. / [Antonio Houaiss e Mauro de Salles Villar; elaborado no Instituto Antônio Houaiss de Lexicografia e Banco de Dados da Língua Portuguesa.] - 4.ed.. Rio de Janeiro: Objetiva, 2010. 
JANNUZZI, Gilberta Sampaio de Martino. Algumas concepções de educação do deficiente. Revista Brasileira de Ciências do Esporte, Porto Alegre, v. 25, n. 3, p. 9-25, maio 2004.

LÜDKE, Menga; ANDRÉ, Marli. Pesquisa em educação: abordagens qualitativas. São Paulo: EPU, 1986.

MAINGUENAU, Dominique. Análise de textos de comunicação. 4a ed. São Paulo: Cortez, 2005.

MANTOAN, Maria Tereza Eglér; PRIETO, Rosângela Gavioli. Inclusão escolar: pontos e contrapontos. 2. ed. São Paulo: Summus, 2006.

MARTINS, José de Souza. Exclusão social e a nova desigualdade. 3.ed. São Paulo: Paulus, 1997.

MATOS, Selma Norberto; MENDES, Enicéia Gonçalves. A proposta de inclusão escolar no contexto nacional de implementação das políticas educacionais. Práxis Educacional (Online), v. 10, p. 33-59, 2014.

STAINBACK, Susan; STAINBACK, Willian. Inclusão: um guia para educadores. Trad. Magda França Lopes. Porto Alegre: Artes Médicas, 1999.

Recebido para publicação em 02 de fevereiro de 2015

Aprovado em 07 de maio de 2015 